\title{
Analysis of Hole Cleaning for a Vertical Well
}

\author{
Bashir Busahmin'1, Nawaf H. Saeid1, Ummul Hasanah Binti Hj Hasan1, Gamal Alusta² \\ ${ }^{1}$ University Teknologi Brunei, Gadong, Brunei Darussalam \\ ${ }^{2}$ United Arab Emirates University, Al Ain, United Arab Emirates \\ Email: bashir.abusahmin@utb.edu.bn
}

How to cite this paper: Busahmin, B. Saeid, N.H., Hasan, U.H.B.H. and Alusta, G. (2017) Analysis of Hole Cleaning for a Vertical Well. Open Access Library Journal, 4: e3579.

https://doi.org/10.4236/oalib.1103579

Received: April 1, 2017

Accepted: May 14, 2017

Published: May 17, 2017

Copyright (c) 2017 by authors and Open Access Library Inc.

This work is licensed under the Creative Commons Attribution International License (CC BY 4.0).

http://creativecommons.org/licenses/by/4.0/

\section{Open Access}

\begin{abstract}
Vertical or straight hole drilling that usually has less than 30 degree still is utilized to drilling operations in conventional and even in unconventional resources in nowadays worldwide for increasing recovery i.e. higher rate of penetration where there are kind of challenges that demand investigation of this type of drilling. One key challenge is efficient hole cleaning or cuttings removal which can lead to issues related to hole problems and consequently problems such as high over pull margins and stuck pipe may occur. Furthermore, inappropriate use of drilling fluid properties at different stages of drilling operation causes the hole to collapse due the accumulation of cuttings in the annulus as well as at the wellbore. The present study introduces an analytical and a numerical model for a vertical well that can be used to optimize drilling operations. The transport velocity i.e. the ration of the annular velocity and slip velocity is so vital in hole cleaning. Inefficient hole cleaning may lead to problems such as, slow drilling rates which increase drilling time and costs. For a vertical well, as addressed in the literature, the proper hole cleaning is basically dependent on drilling hydraulics or mud rheology liked rilling fluid density, viscosity and thixotropy or gel strength. Based on the proposed predictions of the above-mentioned parameters that are significant to avoid formation damage while drilling a vertical hole. The present article analysis the data related to efficient drilling operations, hole cleaning for a vertical well and the results revealed that mud rheology, density, transport velocity, pipe rotation and the depth of the well are the controlling factors that influence hole cleaning.
\end{abstract}

\section{Subject Areas}

Mechanical Engineering

\section{Keywords}

Yield Point, Plastic Viscosity, Rate of Penetration, Mud Weight 


\section{Introduction}

Nowadays; the enhancement of drilling technology is a challenging topic, more specifically when it addresses the economical point of view that, horizontal drilling provides more access to the reservoirs and more oil is produced compared to conventional drilling. Generally; as the horizontal wellbores get longer and/or the inclination angle becomes greater, the percentage of cuttings concentration at the wellbore increases.

In horizontal segment of the wellbore, cuttings accumulate horizontally; thus, the fluid velocity has a reduced horizontal constituent. The percentage of cuttings increases with time at a specific horizontal section. Therefore, less distance will be available for the cuttings to be transferred and eventually hit the borehole wall. Inefficient hole cleaning and formation of beds lead to problems such as: premature bit wear, high torque and drag, stuck pipe and eventually an increase in rotation time and cost. Field data [1] confirm that hole cleaning is still a major problem on most directional wells and many vertical wells, despite significant progress made in drilling fluids, tools, and field practices, along with over 30 years of university and industry research, the more serious hole-cleaning problems can occur when potential risks are underestimated. Mohammadsalehi and Malekzadeh [2] presented a detailed combination of Larsen's model and Moore's correlation to predict and calculate the minimum flow rate for cuttings removal for all range of inclinations namely from $0^{\circ}$ to $90^{\circ}$. The resultant flow rate is compared with flow rate that maximizes the bit horsepower or bit jet impact force. If the flow rate for cuttings removal is less than the optimized flow rate, the latter is selected. But if the flow rate for cuttings removal is higher than the optimized flowrate, then drilling fluid rheological properties should be changed until the optimized flow rate becomes higher than the flow rate for cuttings removal.

Rate of penetration was predicted by applying different bit designs, types and drilling operational parameters versus depth in combination with the apparent rock strength $\log [3]$.

Continuity equation, Navier-Stoke equations, and the power law of nonNewtonian viscosity model were adopted by [4] to establish the mathematical model of the cutting transport process in the annulus of the well. The computational fluid dynamic technique is used to solve the governing equations by using FLUENT commercial code. The specifications of the particles, the pumping head and feeding conditions were obtained from a drilling site in Sudan.

A 3D incompressible non-Newtonian drilling mud flow in a drilling model of a vertical well is considered by [5] for numerical simulations under steady flow conditions and the investigation is limited only to laminar flow at Reynolds number based on the hydraulic diameter of the annular space of $\operatorname{Re}=1150$.

[6] conducted experiments using multiphase flow loop under a wide range of air and water flow rates while introducing cuttings into the annulus with several different amounts. Data has been collected for steady state conditions, i.e. liquid, gas and cuttings injection rates are stabilized. Collection data include flow rates of liquid and gas phases, frictional pressure drop inside the test section, local 
pressures at different locations in the flow loop. [7] addressed a new drill pipe design integrating hydro-mechanical features in each tool joint has been developed to overcome limitations of mechanical hole cleaning devices (MCDs) in smaller diameter holes, and to extend the applications of hydro -clean drill pipe to ERD (Extended Reach Drilling) well. [8] conducted several cuttings transport experiments, using a large-scale flow-loop apparatus and field measurement of annular pressure, using PWD (pressure while drilling) in a geothermal directional well recently drilled in Japan. Numerical simulation for the targeted long extended-reach geothermal well with a total depth $3000 \mathrm{~m}$, horizontal departure of $2500 \mathrm{~m}$, and maximum hole inclination angle of $70^{\circ}$ was performed using a transient hydraulics simulator. [9] explained the effect of the cuttings bed properties on hole cleaning in detail and demonstrated how the drilling operations were improved compared to earlier drilling operations using conventional drilling fluids. From drilling operations in North Sea fields, it is shown how the total drilling progress is improved. [10] developed a transient cuttings-transport model by integrating closure laws for cuttings transport into a transient drilling model. Their model accounts for both fluid transport and drill-string mechanics and how this model was used to monitor two different drilling operations in the North Sea (one using conventional drilling and one using managed-pressure drilling (MPD)). [11] carried out flow-loop experiments to evaluate and compare sweep efficiencies of the fiber sweep [0.47\% Xanthan gum (XG) and 0.04\% synthetic fiber] and the base fluid (0.47\% XG). Equilibrium bed heights were measured at different sweep flow rates in horizontal and inclined configurations. [12] described and modeled a simple and more reliable artificial neural network (ANN) for various borehole conditions using some critical parameters associated with foam velocity, foam quality, hole geometry, subsurface condition (pressure and temperature) and pipe rotation. The average absolute percent relative error (AAPE) between the experimental cuttings concentration and ANN model is less than 6\%, and using MLR, AAPE is less than $9 \%$. Learned lesson by [13] was that in a hole-cleaning situation, increasing fluid rheology moderately could lead to a reduction in equivalent circulating density (ECD). The application was also a good example of hole-cleaning monitoring. By carefully analyzing the cuttings shape and size and by comparing real-time ECD measurements with calculated ECDs, it was possible to quickly detect inefficient hole cleaning. It is advisable by [14] to study the behavior of cuttings transport under different conditions. In general, experimental observations and CFD simulations are main methods to analyze the effects of cutting parameters, fluid parameters and operational parameters on hole cleaning. The correlations and models are applied to predict the number of cuttings and the critical velocity in the annulus. The existing problems and characteristics of these correlations and models were summarized by [15]. Theoretical models and correlations mainly applied to calculate cuttings bed height, critical velocity to provide the guidance for the design of hydraulic parameters and the effects of flow rate, inclination, mud rheology, drill pipe rotation and other factors on hole cleaning, in addition, CFD simulations was applied [16]. 
[17] cuttings transport simulations were carried out for inclinations from $45^{\circ}$ to $90^{\circ}$, for pipe rotation speeds from 80 to 240 rotation per minute, and for flow rates from 30 to 50 Liters per second. Annular cuttings volume, pressure drop, and cuttings distribution are recorded simultaneously within the simulation proceeding.

In real time drilling, mud properties in any type of wells rather are complex with numerous parameters. However, a simplified model was created by [18] as a pre-requisite to understand these complex flow behaviors.

If the flow rate for cuttings removal is less than the optimized flow rate, the latter is selected. The general and main objective for any oil and gas is to maximize oil production safely and economically. One way to achieve that is to increase the penetration rate through the proper choice of the bit nozzles. Moreover, understanding the whole parameters that affect and control hole cleaning for a vertical well is beneficial, therefore a usable is achieved. Table 1 represents some of the measured and calculated the velocity values for different fluid types. A series of simplified hole cleaning charts have been developed by [19] which enabled the optimum hole cleaning parameters to be determined at the rig site, as well as mathematical model of the cuttings transport with foam in vertical wells has been developed and numerically solved. [20] demonstrated the effectivity of results, parameters such as drilling torque, mud returned along the cuttings on the shale shaker and the occurrence of problems associated with poor hole cleaning. Hole cleaning is a major topic in drilling operations, therefore parameters that affect hole cleaning must be investigated. These parameters at the wellbore will include drilling rate, angle of inclination, pipe rotation, yield point, plastic viscosity, cutting size, rate, etc. Based on the importance of the parameters sensitivity analysis was conducted and the result in maintaining the carrying capacity of the drilling fluid is achieved. Moreover, to attain further studies of the cutting accumulations at the wellbore, a real-time drilling data should be obtained, hence proper analysis will be achieved.

Vertical Cutting Slip Velocity (VCSV):

The cutting slip velocity can be modeled and calculated as:

$$
v_{D j}=\frac{t v_{j} A_{j}}{x\left(A_{j+1}+2 A_{j}+A_{j-1}\right)}=0.25 v_{a}
$$

Table 1. Fluid type and slip velocities, (Iyoho's laboratory data), cutting size 1/4 inch.

\begin{tabular}{ccc}
\hline & \multicolumn{2}{c}{ Slip Velocity $(\mathrm{ft} / \mathrm{sec})$} \\
\cline { 2 - 3 } Fluid & Measured & Calculated \\
\hline Water & 0.85 & 0.90 \\
Low-viscosity bentonite & 0.70 & 0.80 \\
High-viscosity bentonite & 0.35 & 0.40 \\
Carpal polymer & 0.45 & 0.45 \\
\hline
\end{tabular}


In Equation (1), the Formation Flow (F) was ignored. where $\Delta \mathrm{x}$ and $\Delta \mathrm{t}$ are the distance between the nodes and the time increment respectively. The values of $\Delta \mathrm{x}=$ element length, 50 and $\Delta \mathrm{t}=$ time step, 25 minutes are used in the present study. It is found that these values are small enough to generate accurate results.

\section{Results and Discussions}

The main point of this study is to investigate the cutting accumulations in a vertical well at the wellbore to minimize hole problems that might occur while drilling. A comparison results between the analytical and numerical approaches presented, where hole problems are mainly associated with the accumulation of cuttings at the wellbore, thus is a function of the physical properties of drilling mud. Figure 1 presents the relationship between flow rate which is the most dominant factor in hole cleaning and the cutting concentration, as it is visible, where the relationship is inversely proportional. Yield point against cutting concentration is shown in Figure 2. Yield point is one of the deciding parameter for the cuttings either to slip or be suspended because of the transport velocity which is the ratio of the annular velocity to the slip velocity related to water based mud or oil based mud, another parameter is the gel strength effect, and that is essential property especially when there is a pump failure and drilling operations stops. It is seen that the cutting concentration increases as the yield point decreases. Yield point is a force to carry or lift the cuttings from the wellbore to the surface. Figure 3 depicts the relationship between the plastic viscosity and the cutting concentrations, it is also clear from this plot that, cutting concentration increases with an increase in the plastic viscosity, which is an indirect relation to the yield point.

Figure 4 presents the numerical result of the cuttings concentrations against depth at different rate of penetration. It is evident that the rate of penetration increases and cutting concentration increases and it is not a depth dependent. Figure 5 presents the cuttings concentrations against time. The cutting concen-

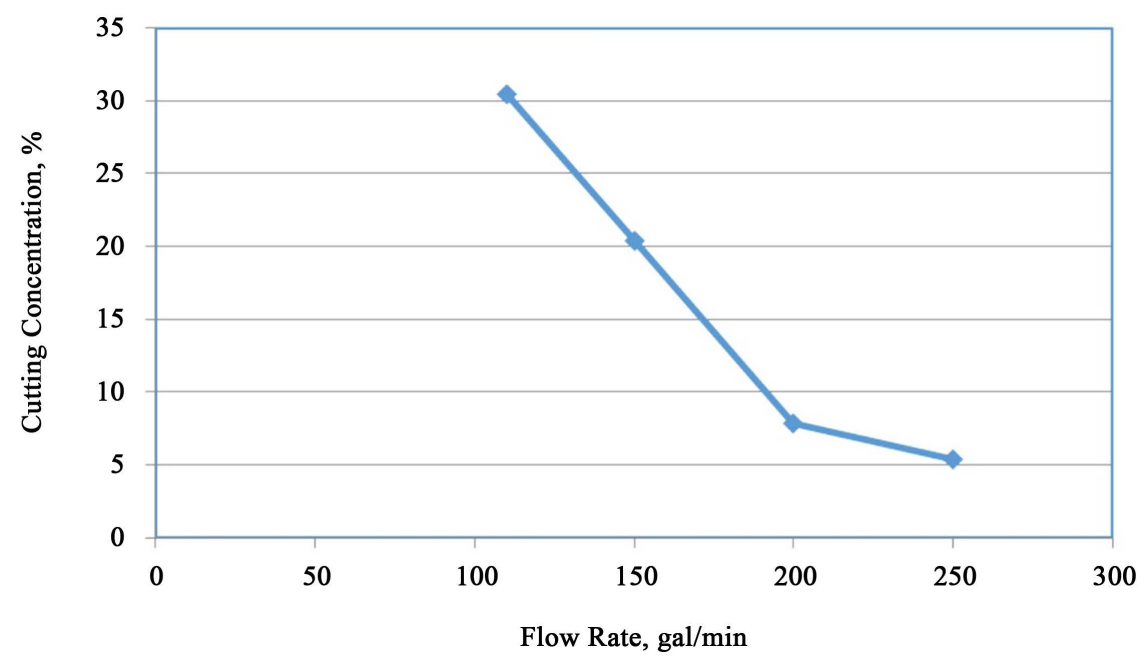

Figure 1. Flowrate against cuttings concentration, analytical model. 


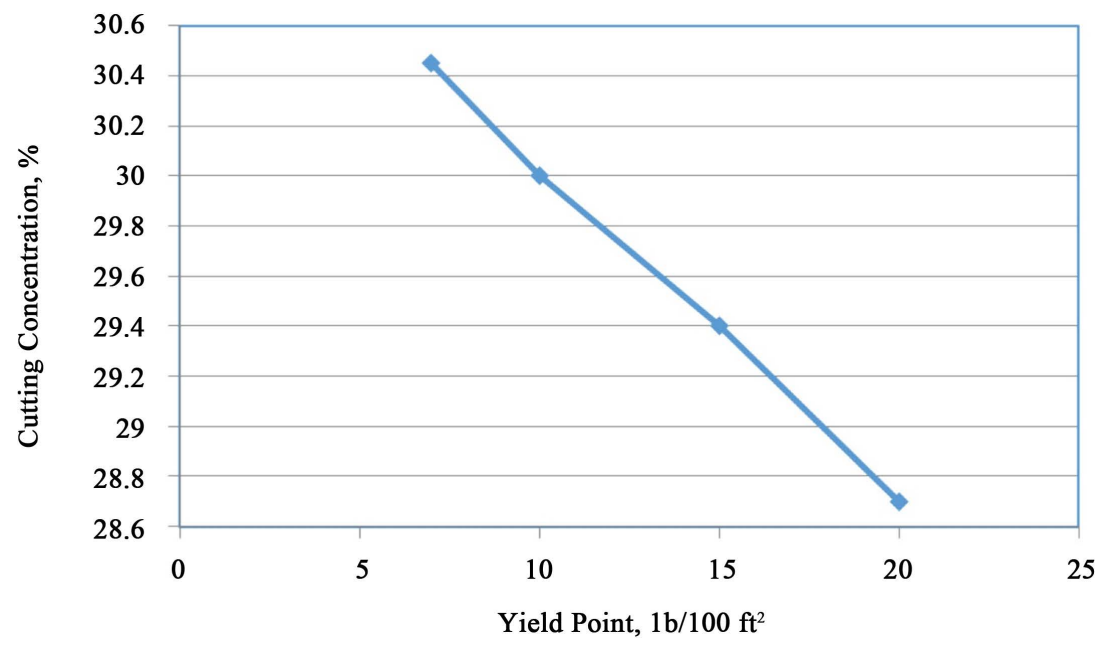

Figure 2. Yield-point against cutting concentration, analytical model.

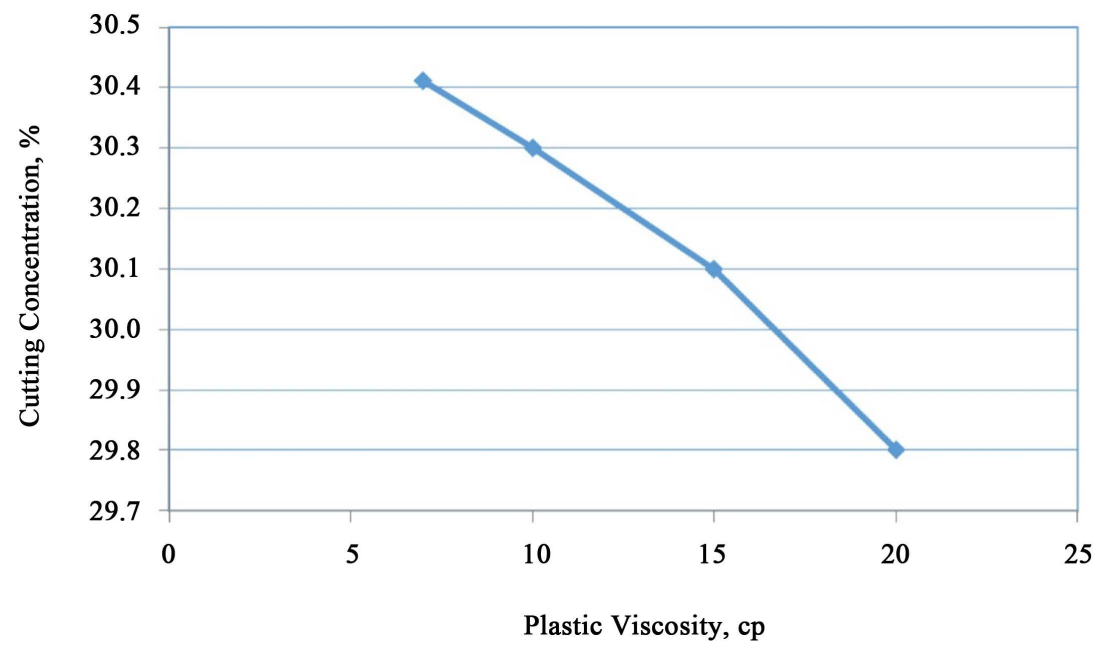

Figure 3. Plastic viscosity against cutting concentration, analytical model.

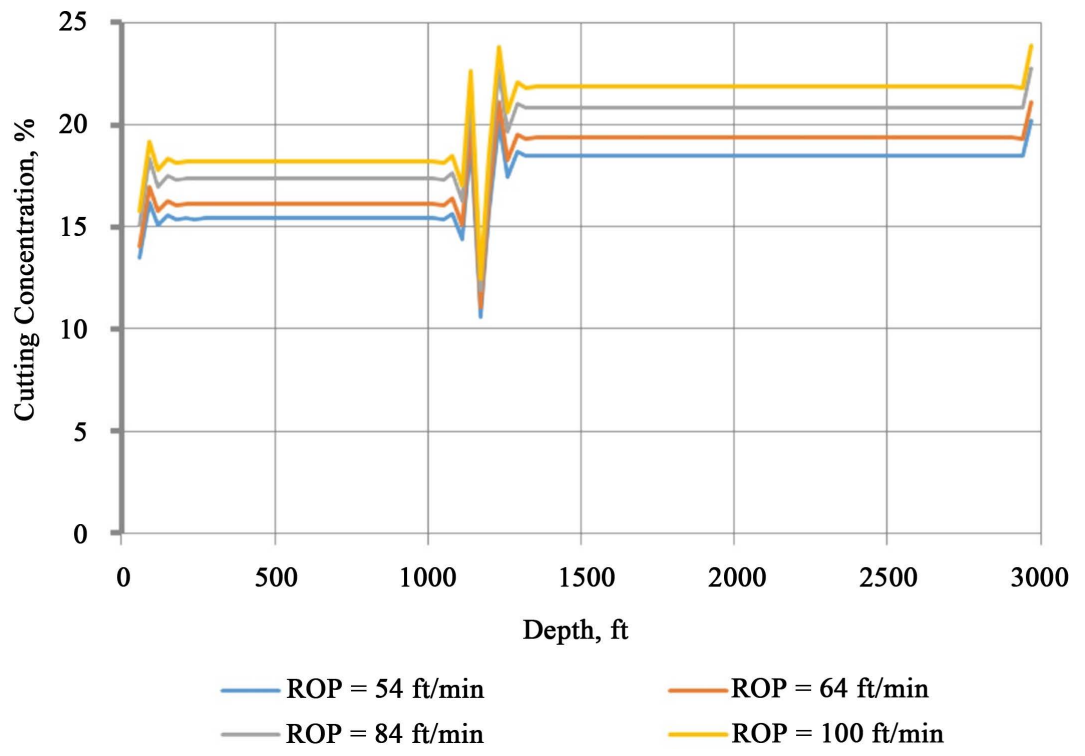

Figure 4. Depth against cutting concentration at various rate of penetration. 
tration is plotted against the depth at different mud weights as it is shown in Figure 6, the results indicate that the behavior looks the same and the model is not dependent on the value of the mud weight, however this might be a good sign for hole cleaning. Figure 7 represents the relationship between flowrate rate and the percentage of cutting concentrations at different plastic viscosities by using a numerical model. Finally, as it is plotted in Figure 8, the relationship between the cuttings concentrations versus time at different flowrates. The result showed that as the time increases along the flowrate there is a decrease in cutting concentration, therefore this might be again a good indication of the hole cleaning.

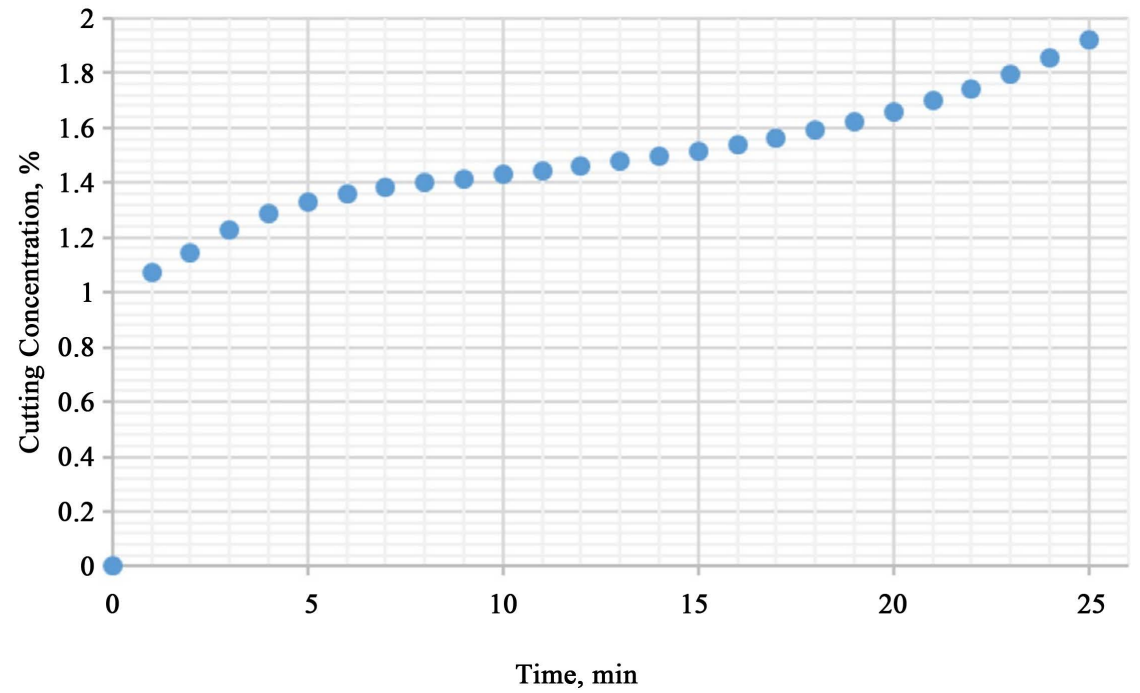

Figure 5. Cutting concentration against time.

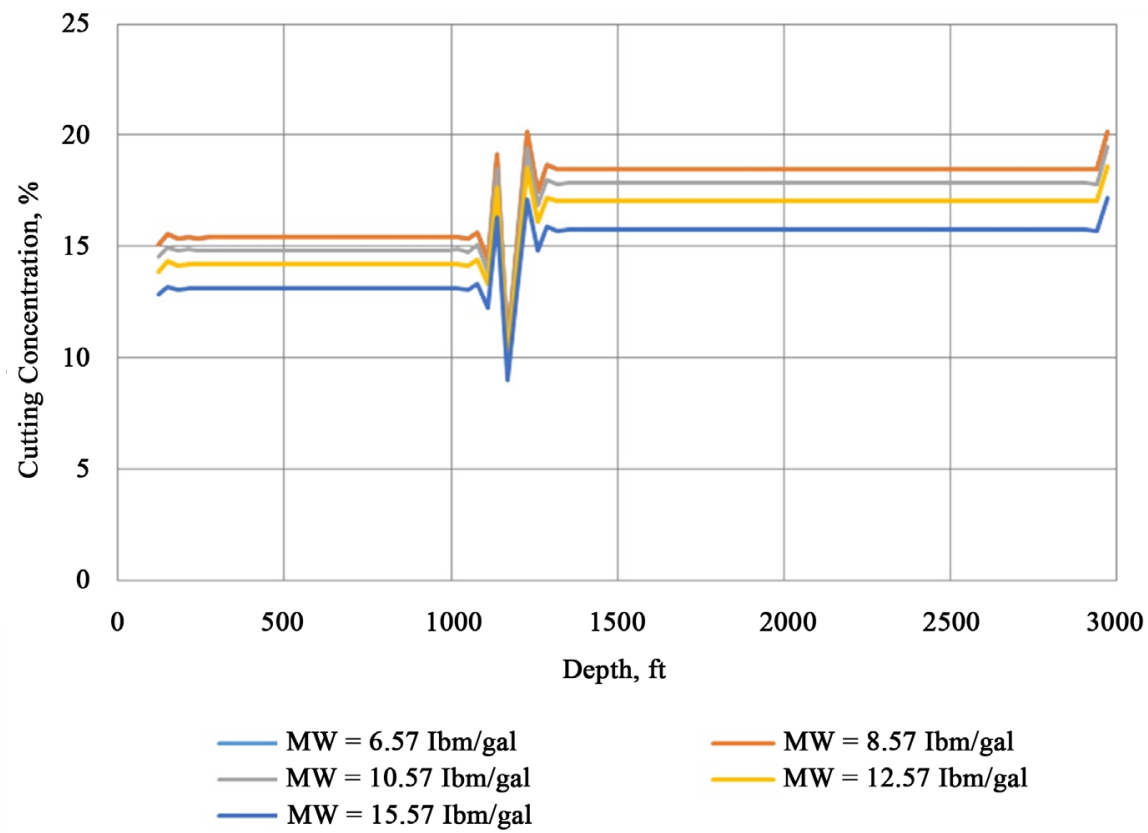

Figure 6. Cutting concentration against time at various mud weight, numerical analysis. 


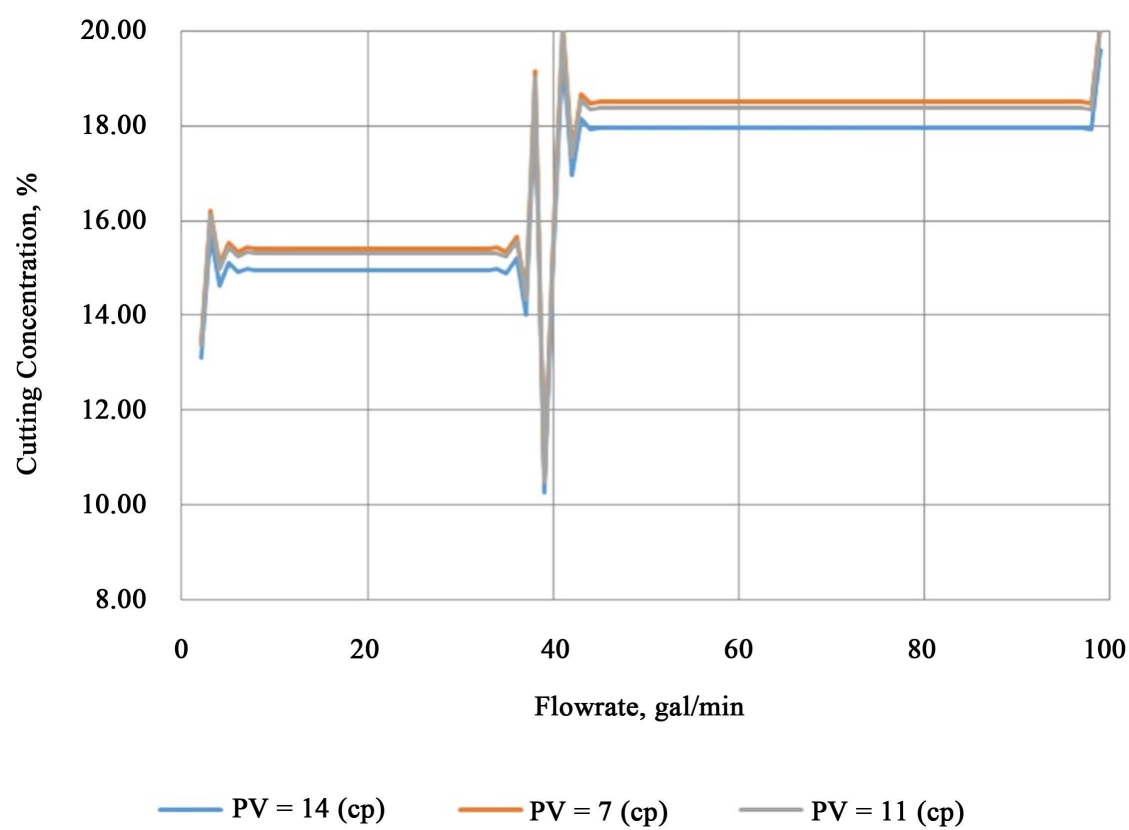

Figure 7. Flowrate against cutting concentration at various plastic viscosities, numerical analysis.

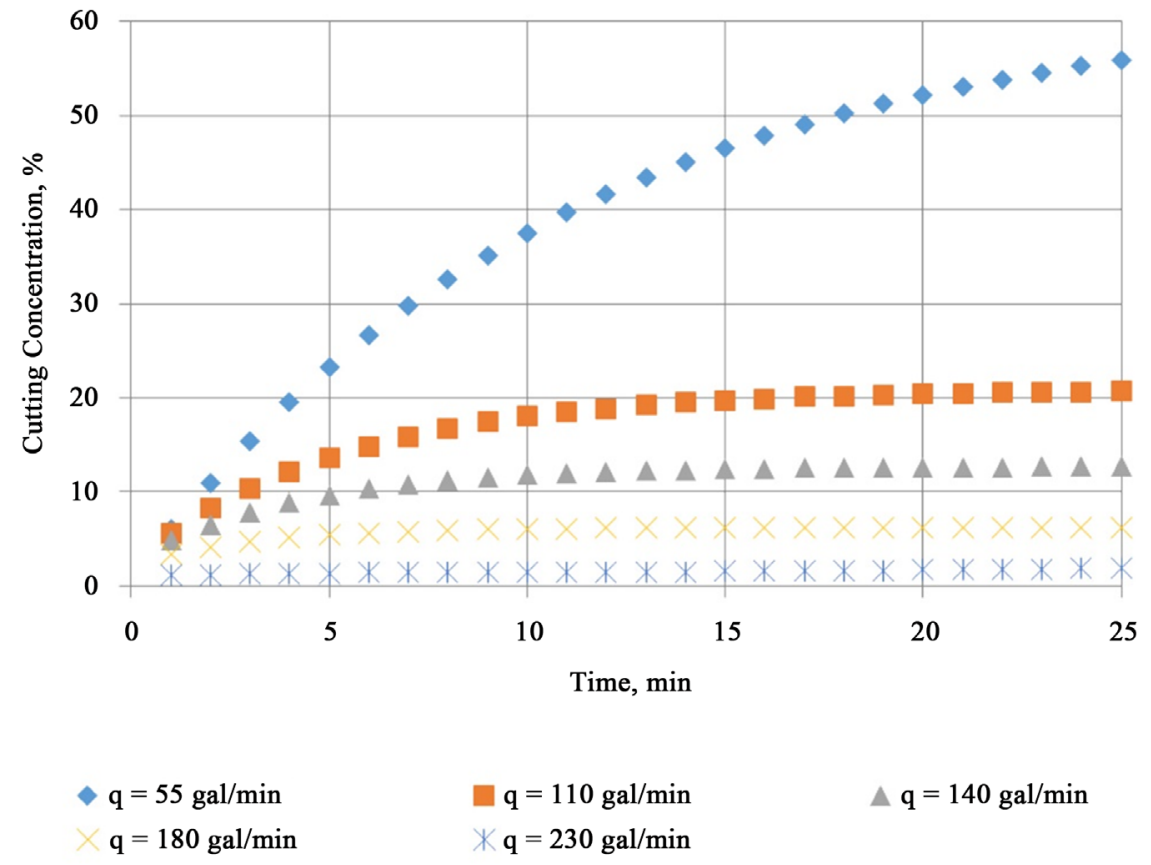

Figure 8. Time against cutting concentration at various flowrates, numerical analysis.

\section{Conclusion}

In this study, hole cleaning is carried out to investigate the effect of different parameters related to the cutting concentrations/accumulation for a vertical well and therefore is analyzed analytically and numerically, the parameters include, flow rate, yield point, plastic viscosity and depth of the well. The results are generated and comparison is carried out between the analytical and numerical ap- 
proaches. Numerical results showed that at high flow rates, cutting concentration decreases as a function of time in addition, cutting concentrations increases with depth as a result, the rate of penetration increases and that indicates a good drilling performance. Moreover, cuttings concentrations are inversely proportional with time.

\section{References}

[1] Aldea, C., Swaco, M.-I. and Iyoho, A.W. (2005) Hole Cleaning: The Achilles ' Heel of Drilling Performance. AADE National Technical Conference and Exhibition AADE-05-NTCE-29, Houston, 5-7 April 2005, 1-9.

[2] Mohammadsalehi, M. and Malekzadeh, N. (2011) Optimization of Hole Cleaning and Cutting Removal in Vertical, Deviated and Horizontal Wells. SPE Asia Pacific Oil and Gas Conference and Exhibition, Jakarta, 20-22 September 2011, SPE143675-MS.

[3] Abdrazakov, S., Hareland, G., Busahmin, B. and Lines, L. (2011) From Seismic to ROP and \$/m for Exploration Wells. 45 th US Rock Mechanics Geotechnics Symposium, San Francisco, 26-29 June 2011, 201 ARMA 11-447.

[4] Al-Kayiem, H.H., MohdZaki, N., Asyraf, M.Z. and Elfeel, M.E. (2010) Simulation of the Cuttings Cleaning During the Drilling Operation. American Journal of Applied Sciences, 7, 800-806. https://doi.org/10.3844/ajassp.2010.800.806

[5] Saeid, N.H. and Busahmin, B. (2016) CFD Analysis of Drilling Fluid Flow in Vertical Well Flow Modeling and Simulation. 6th Brunei International Conference on Engineering and Technology, Brunei, 14-16 November, 2016, 1-16.

[6] Pilehvari, A.A., Azar, J.J. and Shirazi, S.A. (1999) State-of-the-Art Cuttings Transport in Horizontal Wellbores. SPE, 14, 196-200.

[7] EttehadiOsgouei, R., Ozbayoglu, E.M., Ozbayoglu, M.A. and Yuksel, E.H. (2015) A New Model to Determine the Two-Phase Drilling Fluid Behaviors through Horizontal Eccentric Annular Geometry. Energy Sources Recovery Utilization and Environmental Effects, 37, 1756-1765. https://doi.org/10.1080/15567036.2011.561275

[8] Van Puymbroek, L. (2013) Increasing Drilling Performance using Hydro-Mechanical Hole Cleaning Devices. SPE 164005 Paper Presented in Muscat, Oman, 28-30 January 2013, 28-30.

[9] Naganawa, S. and Okabe, T. (2014) Comprehensive Studies on Hole Cleaning and ECD Management in Long Extended-Reach Geothermal Well Drilling. ThirtyNinth Workshop on Geothermal Reservoir Engineering Stanford University, Stanford, California, SGP-TR-202.

[10] Saasen, A. and Løklingholm, G. (2002) The Effect of Drilling Fluid Rheological Properties on Hole Cleaning, SPE-74558-MS. IADC/SPE Drilling Conference, Dallas, 26-28 February 2002, 1-5.

[11] Cayeux, E., Mesagan, T., Tanripada, S., Zidan, M. and Fjelde, K.K. (2014) Real-Time Evaluation of Hole-Cleaning Conditions with a Transient Cuttings-Transport Model, SPE-163492-PA. SPE Drilling \& Completion, 29, 1-17.

[12] Ahmed, R.M. and Takach, N.E. (2009) Fiber Sweeps for Hole Cleaning, SPE113746-PA. SPE Drilling \& Completion, 24, 1-10.

[13] Rooki, R., Ardejani, F.D. and Moradzadeh, A. (2014) Hole Cleaning Prediction in Foam Drilling Using Artificial Neural Network and Multiple Linear Regression, Scientific Journal. Geomaterials, 4, 47-53. https://doi.org/10.4236/gm.2014.41005

[14] Yan, T., Sun, X.F., Shao, S. and Luan, S.Z. (2013) Review and Analysis of Cuttings 
Transport in Complex Structural Wells Wang Kelin. The Open Fuels \& Energy Science Journal, 6, 9-17.

[15] Wang, K.L., Yan, T., Sun, X.F., Shao, S. and Luan, S.Z. (2013) Review and Analysis of Cuttings Transport in Complex Structural Wells. The Open Fuels \& Energy Science Journal, 6, 9-17. https://doi.org/10.2174/1876973X20130610001

[16] Sun, X.F., Wang, K.L., Yan, T., Zhang, Y., Shao, S. and Luan, S. (2013) Review of Hole Cleaning in Complex Structural Wells. The Open Petroleum Engineering Journal, 6, 25-32. https://doi.org/10.2174/1874834101306010025

[17] Sun, X., Wang, K., Yan, T., et al. (2014) Effect of Drillpipe Rotation on Cuttings Transport Using Computational Fluid Dynamics (CFD) in Complex Structure Wells. Petrol Exploration Production Technology, 4, 255-261. https://doi.org/10.1007/s13202-014-0118-x

[18] Saeid, N.H. and Abusahmin, B.S. (2016) Numerical Investigations of Drilling Mud Flow Characteristics in Vertical Well. IRACST-Engineering Science and Technology: An International Journal (ESTI), 6, 16-22.

[19] Li, Y.B. and Kuru, E. (2004) Optimization of Hole Cleaning in Vertical Wells Using Foam. SPE International Thermal Operations and Heavy Oil Symposium and Western Regional Meeting, Bakersfield, 16-18 March 2004, 34. https://doi.org/10.2118/86927-ms

[20] Mohammadsalehi, M. and Malekzadeh, N. (2011) Application of New Hole Cleaning Optimization Method within All Ranges of Hole Inclinations, IPTC 14154 Iranian Central Oil Fields Company (ICOFC). International Petroleum Technology Conference, Bangkok, 10.2523/IPTC-14154-MS.

\section{Nomenclature}

Re: Reynolds number

Cp: Plastic viscosity (centipoise)

Yp: Yield point (pound per hundred feet square)

ROP: Rate of penetration (feet per minute)

MW: Mud weight (pound per gallon)

q: Flow rate (gallon per minute)

D: depth (feet)

$\mathrm{t}$ : time (minute) 